\title{
Attitudes toward and willingness to work with older people among undergraduate nursing students in a public university in Sri Lanka: A cross sectional study
}

\author{
Sarath Rathnayake ${ }^{\mathrm{a}, *, 1}$, Yamuna Athukorala ${ }^{\mathrm{a}, 1}$, Sidiah Siop ${ }^{\mathrm{b}, 2}$ \\ a Department of Nursing, Faculty of Allied Health Sciences, University of Peradeniya, Peradeniya, Sri Lanka \\ b Department of Nursing, Faculty of Medicine and Health Sciences, Universiti Malaysia Sarawak, Sarawak, Malaysia
}

\section{A R T I C L E I N F O}

\section{Article history:}

Accepted 9 October 2015

\section{Keywords:}

Attitudes

Work preference

Older people

Nursing students

Sri Lanka

\begin{abstract}
S U M M A R Y
Background: With the increased number of older people globally, caring for older people has become a challenge for many countries. Nurses have a pivotal role in providing quality care for older people and care is affected by their attitudes. The preparation of nurses to deliver quality care needs to be instilled during their studying in the Schools of Nursing.

Objective: To examine the attitudes of nursing students toward and their willingness to work with older people in Sri Lanka.

Methodology: A purposive sample of 98 first to fourth year undergraduate nursing students in the Department of Nursing, University of Peradeniya completed a self-administered questionnaire consisting of socio-demographic variables, Kogan's Attitudes toward Older People Scale, and questions related to willingness to work with older people.

Results: Fifty percent of the respondents $(\mathrm{n}=49)$ held slightly positive attitudes toward older people while $45 \%(n=44)$ held slightly negative attitudes. About one-third of the respondents $(29.9 \%, n=29)$ selected the elderly group as the least preferred group for their future career from the categorized seven age groups. Only $5.1 \%(n=5)$ of the respondents ranked the elderly group as the first preferred group. There was a significant difference in attitudes between students who lived with older people and students who did not live with older people $(t=2.565, p=.012)$. There was a positive relationship between attitudes and preference for working with older people $(r=.342, p=.001)$.

Conclusion: Nursing students have moderately positive attitudes toward older people; however, they show little interest in working with older people. Living with older people develops positive attitudes of young people toward older people. Attitudes are related to the selection in area of specialty in nursing. Nursing curricula need to include Gerontological Nursing as a major area.
\end{abstract}

(C) 2015 Elsevier Ltd. All rights reserved.

\section{Introduction}

The increasing number of elderly persons is a global phenomenon and Sri Lanka, a developing country located in the South Asian region is also experiencing this rapid demographic change. In 2012, the elderly population of Sri Lanka, aged 60 and over, was reported as 2.52 million representing $12.4 \%$ of the total population (Department of Census and Statistics, 2012). With this increased number of older people, the health sector of Sri Lanka faces a serious challenge in meeting their health

\footnotetext{
* Corresponding author. Tel.: + 94 812388820; fax: + 94812387394.

E-mail addresses: sarathr@pdn.ac.lk (S. Rathnayake),yamunarathukorala@gmail.com (Y. Athukorala), jsidiah@fmhs.unimas.my (S. Siop).

1 Tel.: + 94812388820 ; fax: +94812387394.

2 Tel.: + 6082 581000x5511; fax: + 6082665152 .
}

needs. As nurses are key people in caring, they have challenging roles in meeting the nursing needs of older people.

Aging is associated with health problems such as increasing diseases and functional disabilities (Browning and Thomas, 2013; Henderson et al, 2008; Liu et al, 2012). Most of the age-related problems are chronic, that require long term management. This phenomenon increases greater demand on nursing care. National studies showed that the prevalence of chronic diseases and functional disabilities were high among older people (Malhotra et al, 2010; Nanayakkara, 2009; Rathnayake and Siop, 2015; Weerasuriya and Jayasinghe, 2005) and non-communicable diseases were the leading cause of hospital deaths in the country (Ministry of Health, 2012). According to Rannan-Eliya (2007), aging is a significant cost driver in national health expenditure in Sri Lanka. According to his projection, expenditure for noncommunicable diseases will continue to increase for cardiovascular diseases, chronic respiratory diseases and diabetes mellitus specifically. 